\title{
TRPM2 confers susceptibility to social stress but is essential for behavioral flexibility
}

\section{AUTHOR(S):}

Andoh, Chihiro; Nishitani, Naoya; Hashimoto, Emina; Nagai, Yuma; Takao, Keizo; Miyakawa, Tsuyoshi; Nakagawa, Takayuki; ... Nagayasu, Kazuki; Shirakawa, Hisashi; Kaneko, Shuji

\section{CITATION:}

Andoh, Chihiro ... [et al]. TRPM2 confers susceptibility to social stress but is essential for behavioral flexibility. Brain Research Reviews 2019, 1704: 68-77

\section{ISSUE DATE:}

2019-02-01

URL:

http://hdl.handle.net/2433/241623

\section{RIGHT:}

(c) 2019. This manuscript version is made available under the CC-BY-NC-ND 4.0 license

http://creativecommons.org/licenses/by-nc-nd/4.0/:; The full-text file will be made open to the public on 1 February 2020 in accordance with publisher's 'Terms and Conditions for Self-Archiving'.; This is not the published version. Please cite only the published version.; この論文は出版社版でありません。引用の際には出版社版をご確認ご利用ください。 


\section{Accepted Manuscript}

Research report

TRPM2 confers susceptibility to social stress but is essential for behavioral flexibility

Chihiro Andoh, Naoya Nishitani, Emina Hashimoto, Yuma Nagai, Keizo Takao, Tsuyoshi Miyakawa, Takayuki Nakagawa, Yasuo Mori, Kazuki Nagayasu, Hisashi Shirakawa, Shuji Kaneko

PII: S0006-8993(18)30496-7

DOI: https://doi.org/10.1016/j.brainres.2018.09.031

Reference: BRES 45963

To appear in: Brain Research

Received Date: 22 March 2018

Revised Date: 19 September 2018

Accepted Date: 21 September 2018

Please cite this article as: C. Andoh, N. Nishitani, E. Hashimoto, Y. Nagai, K. Takao, T. Miyakawa, T. Nakagawa, Y. Mori, K. Nagayasu, H. Shirakawa, S. Kaneko, TRPM2 confers susceptibility to social stress but is essential for behavioral flexibility, Brain Research (2018), doi: https://doi.org/10.1016/j.brainres.2018.09.031

This is a PDF file of an unedited manuscript that has been accepted for publication. As a service to our customers we are providing this early version of the manuscript. The manuscript will undergo copyediting, typesetting, and review of the resulting proof before it is published in its final form. Please note that during the production process errors may be discovered which could affect the content, and all legal disclaimers that apply to the journal pertain. 


\section{Research Paper}

\section{TRPM2 confers susceptibility to social stress but is essential for behavioral flexibility}

Chihiro Andoh ${ }^{\mathrm{a}, \mathrm{g}}$, Naoya Nishitani ${ }^{\mathrm{a}, \mathrm{g}}$, Emina Hashimoto ${ }^{\mathrm{a}, \mathrm{g}}$, Yuma Nagai ${ }^{\mathrm{a}}$, Keizo Takao ${ }^{\mathrm{b}, \mathrm{c}}$, Tsuyoshi Miyakawa ${ }^{\text {b,d, }}$, Takayuki Nakagawa ${ }^{\mathrm{e}}$, Yasuo Mori ${ }^{\mathrm{g}}$, Kazuki Nagayasu ${ }^{\mathrm{a}}$, Hisashi Shirakawa $^{\mathrm{a},{ }^{*}, \text { Shuji Kaneko }}{ }^{\mathrm{a}}$

a: Department of Molecular Pharmacology, Graduate School of Pharmaceutical Sciences, Kyoto University, Kyoto, Japan.

b: Center for Genetic Analysis of Behavior, National Institute for Physiological Sciences, Okazaki, Japan.

c: Life Science Research Center, University of Toyama, Toyama, Japan.

d: Division of Systems Medical Science, Institute for Comprehensive Medical Science, Fujita Health University, Toyoake, Japan.

e: Department of Clinical Pharmacology and Therapeutics, Kyoto University Hospital, Kyoto, Japan.

f: Department of Synthetic Chemistry and Biological Chemistry, Graduate School of Engineering, Kyoto University, Kyoto, Japan.

g: These authors contributed equally to this work 
*. Corresponding author:

Dr. Hisashi Shirakawa

Department of Molecular Pharmacology, Graduate School of

Pharmaceutical Sciences, Kyoto University,

46-29 Yoshida-Shimoadachi-cho, Sakyo-ku, Kyoto 606-8501, Japan

Tel: +81-75-753-4549; Fax: +81-75-753-4548.

E-mail: shirakaw@pharm.kyoto-u.ac.jp

Abstract: 205 words

Length of article: 8540 words

Number of references: 44 references

Number of figures: 6 figures

Number of tables: 1 table

Declarations of interest: none 


\section{Abstract}

Transient receptor potential melastatin 2 (TRPM2) is a $\mathrm{Ca}^{2+}$-permeable, nonselective cation channel and a member of the TRP channel superfamily that acts as a sensor of intracellular redox states. TRPM2 is widely distributed in many tissues and highly expressed in the brain, but the physiological roles of TRPM2 in the central nervous system remain unclear. In this study, TRPM2-deficient mice were examined in a series of behavioral tests. TRPM2-deficient mice did not significantly differ from wild-type littermates in muscle strength, light/dark transition test, rotarod, elevated plus maze, social interaction, prepulse inhibition, Y-maze, forced swim test, cued and contextual fear conditioning, and tail suspension test. In the Barnes circular maze, TRPM2-deficient mice learned the fixed escape box position at similar extent to wild-type littermates, suggesting normal reference memory. However, performance of the first reversal trial and probe test were significantly impaired in TRPM2-deficient mice. In the T-maze delayed alternation task, TRPM2 deficiency significantly reduced choice accuracy. These results indicate that TRPM2-deficient mice shows behavioral inflexibility. Meanwhile, social avoidance induced by repeated social defeat stress was significantly attenuated in TRPM2-deficient mice, suggesting that TRPM2 deficiency confers stress resiliency. Our findings indicate that TRPM2 plays an essential role in maintaining behavioral flexibility but it increases susceptibility to stress.

Key words: TRPM2, stress resiliency, behavioral inflexibility 


\section{Introduction}

Transient receptor potential melastatin 2 (TRPM2) is a member of the TRP channel superfamily, a diverse group of voltage-independent, calcium-permeable nonselective cation channels, and highly expressed in brain and inflammatory cells. TRPM2 channels possess an intracellular domain activated by intracellular messengers such as ADP-ribose (ADPR), nicotinamide adenine dinucleotide $\left(\mathrm{NAD}^{+}\right.$), and cyclic ADPR (cADPR) [1] and likely acts as a sensor for reactive oxygen species including hydrogen peroxide $\left(\mathrm{H}_{2} \mathrm{O}_{2}\right)$ [2]. TRPM2 is also activated by warm temperature $\left(>35^{\circ} \mathrm{C}\right)$ and cADPR under warm conditions in pancreatic $\beta$ cells [3].

In the periphery, TRPM2 is important for insulin secretion in pancreatic $\beta$ cells, and its deficiency causes an increased blood glucose level [3, 4]. Yamamoto et al. reported that TRPM2 plays a pivotal role in the production of chemokines by monocytes/macrophages, and the infiltration of neutrophils at inflamed sites [5]. On the other hand, TRPM2 was first cloned from the cDNA library of fetal brain [6]. Recently, human genomic studies suggest a relationship between TRPM2 and bipolar disorder [7-9]. Moreover, TRPM2 is functionally expressed in microglia [10], cortical neurons [11], hippocampal neurons [12] and dopaminergic neurons [13]. Furthermore, hippocampal long-term depression is impaired in TRPM2-deficient mice [14], indicating the possible involvement of TRPM2 in memory maintenance. However, the physiological roles of TRPM2 in the central nervous system still remain unclear.

TRPM2-deficient mice are viable, fertile, and largely indistinguishable from wild-type (WT) littermates in general appearance and behavior, although detailed 
behavioral analyses have not been performed. In this study, we conducted comprehensive behavioral tests on TRPM2 knock-out mice to clarify the physiological roles of TRPM2 in the central nervous system.

\section{Results}

\subsection{Normal physical characteristics and locomotor activity}

TRPM2-deficient mice and WT littermates were first evaluated for their general behavioral characteristics. TRPM2-deficient mice and WT mice did not significantly differ in overall health and appearance, body weight, body temperature, grip strength, or wire hang (Fig. 1A). To evaluate the locomotor activity of TRPM2-deficient mice, we observed their behavior in a novel open field environment. TRPM2-deficient mice did not differ significantly from WT mice in total distance, vertical activity, center time, or stereotypic counts in the open field test (Fig. 1B). These results suggest that mice lacking TRPM2 possess normal physical and locomotor activity. In addition, TRPM2-deficient mice and WT mice did not significantly differ in the light/dark transition test, rotarod, elevated plus maze, social interaction, prepulse inhibition, Y-maze, forced swim test, or tail suspension test (Tables 1).

\subsection{Normal spatial working memory in eight-arm radial maze}

To examine spatial working memory, the eight-arm radial maze test was conducted.

During the learning period, we used the number of different arm choices in the first 
eight entries, the number of revisiting errors, and latency to visit all eight arms to evaluate memory (Fig. 2A-C). Following 16 normal learning trials, mice experienced delay trials during which they were confined in arms for 30, 120, or $300 \mathrm{sec}$ (Fig. 2D). TRPM2-deficient mice and WT mice showed a similar performance in both the learning and delay periods.

\subsection{Behavioral inflexibility in Barnes maze reversal task and T-maze delayed forced alternation task}

We examined spatial reference memory using a Barnes circular maze (Fig. 3A-F). Memory formation was estimated using distance traveled, latency, and error number before reaching the correct target hole. During the learning trials (trials 1-12), TRPM2-deficient mice and WT mice learned the fixed position of an escape hole in a similar manner. No significant difference was seen in probe tests (observation without escape box) after $24 \mathrm{hr}$ (Fig. 3D) and 1 week (Fig. 3E), suggesting that TRPM2-deficient mice can memorize the position of an escape box and retain the memory even after a 1 week retention.

Then we investigated behavioral flexibility in Barnes maze reversal task. At trial 20, when the escape box was placed at the opposite side, TRPM2-deficient mice demonstrated perseveration to the old escape box location and more error before arriving at the new correct escape box $(\mathrm{t}(912)=3.18, \mathrm{p}=.0497)$, and they tended to travel a longer distance than WT littermates. No difference was observed in trials $21-25$, indicating TRPM2-deficient mice maintain the ability to remember the new escape box 
location. However, the third probe test after six reverse trials revealed a tendency of TRPM2-deficient mice to stay near the new correct target hole for less time than the WT mice (Fig. 3F). When comparing time spent near the old and new correct target hole, WT mice stayed significantly longer near the new target $(\mathrm{t}(19)=2.19, \mathrm{p}=.0409$; paired $t$-test), but TRPM2-deficient mice did $\operatorname{not}(\mathrm{t}(19)=1.73, \mathrm{p}=.1004$; paired $t$-test).

The T-maze forced alternation task is a test in which mice are rewarded when they choose the arm that they did not choose on the previous turn. TRPM2-deficient mice and WT mice did not significantly differ in their latency to finish the set of 10 choices and percentage of correct choices made (Fig. 4A, B). To increase the difficulty of the task, a delay period $(10,30$, or $60 \mathrm{~s})$ was applied. TRPM2-deficient mice demonstrated a lower percentage of correct choices than WT littermates when $30 \mathrm{sec}$ delay was applied $(\mathrm{t}(27)=2.31, \mathrm{p}=.0289 ;$ Fig. $4 \mathrm{C})$.

In another T-maze protocol involving left-right discrimination, mice must remember a fixed correct route choice. We conducted 10 normal trials, followed by eight reverse trials in which the correct route with food reward was changed to the opposite side. The correct percentage gradually improved during normal trials, although it dropped at the beginning of the reverse trials (Fig. 5A). Its variation was similar between TRPM2-deficient and WT mice. The latency to finish one trial (composed of 10 choices) fluctuated (Fig. 5B) because a maximum of three trials can be performed in one day, and latency tends to be worse on the first trial of the day. The results of TRPM2-deficient mice were similar to those of WT mice in both normal and reverse trials. 


\subsection{TRPM2-deficient mice shows resiliency to repeated social defeat stress}

To investigate stress resiliency and susceptibility of TRPM2-deficient mice, we employed repeated social defeat stress model [15]. After repeated social defeat for 10 days, we performed social interaction test. We found that TRPM2-defecient mice spent significantly more time in interaction zone $(\mathrm{t}(54)=2.87, \mathrm{p}=.0059$; Fig. 6A, B), less time in avoidance zone $(\mathrm{t}(54)=2.91, \mathrm{p}=.0052$; Fig. $6 \mathrm{C})$, compared to WT mice. Interaction ratio of TRPM2-deficient mice was significantly higher than that of WT mice $(\mathrm{t}(54)=2.36, \mathrm{p}=.0218$; Fig. $6 \mathrm{D})$. On the other hand, serum corticosterone level after repeated social defeat stress in TRPM2-deficient mice was not significantly different with that in WT mice (two-way ANOVA, genotype effect: $F(1,30)=2.21$, p $=.147$, stress effect: $F(1,30)=154, p<.0001$, interaction: $F(1,30)=4.91, p=.0345$; WT-CSDS vs. TRPM2-deficient-CSDS, $\mathrm{p}=.107$, Tukey's multiple comparisons test; Fig. 6E). Furthermore, there was no significant difference in the time spent in the open arm in the elevated-plus maze test between WT and TRPM2-deficient mice after repeated social defeat $(\mathrm{t}(25)=0.798, \mathrm{p}=.432$; Fig. $6 \mathrm{~F})$.

\section{Discussion}

In this study, we performed comprehensive analysis of the behavioral properties of TRPM2-deficient mice. Although TRPM2-deficient mice did not demonstrate obvious abnormalities in most of behavioral tests, behavioral inflexibility and resiliency to social stress was observed. 
In the eight-arm radial maze test, performance of TRPM2-deficient mice was similar to that of WT mice, suggesting that TRPM2-deficient mice have normal spatial working memory. Furthermore, in the Barnes maze test before reversal session and T-maze left-right discrimination task, TRPM2-deficient mice show similar performance to WT mice. These results indicate that TRPM2-deficient mice have normal spatial reference memory. By contrast, when the escape box was moved to the opposite side in the Barnes maze test, the error rate of TRPM2-deficient mice was higher than that of WT mice. Similarly, in the T-maze forced alternation task, correct choice accuracy of TRPM2-deficient mice was lower than that of WT mice when a $30 \mathrm{sec}$ delay was applied. Taken together, these results indicate that TRPM2-deficient mice show behavioral inflexibility. However, we have to note that there was no difference in the error rate in the Barnes maze test between WT and TRPM2-deficient mice in 2nd to 6th reversal trials, indicating that behavioral inflexibility observed in TRPM2-deficient mice is relatively moderate.

Interestingly, the difference between TRPM2-deficient and WT mice in the Barnes maze disappeared with continuous reversal training. Fabricius et al. reported that mice that experienced maternal separation demonstrated poor performance in the reverse trial, and their performance became similar to that of WT mice during continuous training [16]. Mice with maternal separation lose a significant number of neurons in the dentate gyrus compared to controls. Since rats with hippocampal damage show perseverative behavior [17], TRPM2, which is functionally expressed in hippocampus [12, 18, 19], may also be related to this result. 
Behavioral flexibility is not a function of the hippocampus alone [20,21], and neonatal lesion of the medial prefrontal cortex has been reported to make rats perseverative [22]. In contrast, perseverative behavior was not observed when the prefrontal cortex was damaged in adulthood [22]. Considering that TRPM2 is expressed in cortical neurons [11], it is possible that behavioral inflexibility observed in this study may be due to deficiency of cortical TRPM2 during the developmental stage.

Dopamine is also important for behavioral flexibility. D1 receptor stimulation [23], D2/D3 receptor deficiency [24], and striatal D2 receptor overexpression [25] all impair behavioral flexibility. Particularly in the T-maze, D3 receptor-deficient mice demonstrate impaired performance only in trials with a delay [24]. Recently, TRPM2-like current was determined in dopamine neurons [13, 26]. Because TRPM2 is a non-selective cation channel, deficiency of TRPM2 may attenuate the activity and/or responsiveness of dopamine neurons, and subsequent D3 receptor signaling, although further electrophysiological and neurochemical analysis is needed.

In this study, the performance of TRPM2-deficient mice was depressed in the reverse trial of the Barnes maze but not in T-maze left-right discrimination task. In T-maze left-right discrimination task, correct choice accuracy was dropped to around $20 \%$ in the first reversal session both in WT and TRPM2-deficient mice. Considering that correct choice accuracy reached the plateau at around $80 \%$ at Trial $7-10$, mice chooses incorrect side in around $20 \%$ of the session even after extensive learning probably due to impulsivity. Therefore, accuracy of around $20 \%$ in the first reversal session may be lower limits in this setting. Taken together, it is possible that this floor effect may 
conceal the difference between WT and TRPM2-deficient mice in T-maze left-right discrimination task.

TRPM2 activator $\mathrm{H}_{2} \mathrm{O}_{2}$ has been reported to relate to memory. In hippocampal slices, $\mathrm{H}_{2} \mathrm{O}_{2}$ prevents induction of new LTP and enhances LTD [27-29]. Mice in which LTD was enhanced by D-serine demonstrate improved performance in the Morris water maze reversal task [30], and forebrain-specific calcineurin-knockout mice with significantly diminished LTD show poor performance in the Morris water maze and radial maze [31]. Considering that LTD is impaired in hippocampal slices prepared from TRPM2-deficient mice [14], this impaired LTD may underlie the behavioral inflexibility observed in this study. As the possible limitation of this study, we have to note that we cannot fully rule out the possibility that previous behavioral experiments might mask the difference between WT mice and TRPM2-deficient mice, although the order of experiments was designed to minimize possible effect to subsequent experiments.

In repeated social defeat stress paradigm [15], we found that TRPM2-deficient mice were resilient to social defeat stress. The precise mechanism underlying this anti-depressive phenotype in TRPM2-deficient mice is unknown. However, we observed that serum corticosterone level after repeated social defeat stress tended to decrease in TRPM2-deficient mice, and significant interaction between stress and genotype in serum corticosterone level. In this context, very recent studies clearly demonstrate that repeated social defeat stress induces activation of mPFC microglia through TLR2/4, which leads to neuronal and behavioral changes through inflammation-related cytokines, such as TNF $\alpha$ [43] and TRPM2-gene knockout markedly attenuates microglial 
activation and resultant production of pro-inflammatory cytokines including TNF $\alpha$ in the corpus callosum of mice with chronic cerebral hypoperfusion [44]. Therefore it might be possible that stress response of TRPM2-deficient mice is attenuated, although further biochemical and behavioral analysis is needed.

Previous studies have demonstrated that oxidative stress such as $\mathrm{H}_{2} \mathrm{O}_{2}$ are involved in the pathology of depression [32]. Recently Ibi et al. reported that genetic deletion of mouse Noxl gene, coding a catalytic subunit of NADPH oxidase generating superoxide, confers resiliency to repeated social defeat stress [33]. Heterozygous deletion of mouse p47phox gene, coding a regulatory subunit of NADPH oxidase, ameliorates behavioral abnormality induced by repeated restraint stress [34]. Because TRPM2 is activated by $\mathrm{H}_{2} \mathrm{O}_{2}$, which is generated through degradation of superoxide, it is possible that oxidative stress induced by NADPH oxidase and subsequent activation of TRPM2 may contribute to social avoidance induced by repeated social defeat stress.

In addition to oxidative stress, monoamine neurons such as dopamine, and serotonin neurons play a key role in regulating susceptibility to social defeat stress [35-38]. Interestingly, dopamine neurons in the ventral tegmental area (VTA) are hyperactive after repeated social defeat [35]. Moreover, optogenetic stimulation of VTA dopamine neurons increases susceptibility to social defeat stress [37]. Considering that TRPM2-like current is observed in dopamine neurons as mentioned above $[13,26]$, hypoactivity of dopamine neurons may underlie both behavioral inflexibility and resiliency to social defeat stress observed in TRPM2-deficient mice. 


\section{Conclusion}

We performed comprehensive behavioral test of TRPM2-deficient mice. There was no difference in most tests, but TRPM2-deficient mice showed behavioral inflexibility in Barnes maze reversal task and T-maze forced alternation task. In repeated social defeat stress paradigm, TRPM2-deficient mice showed resiliency to social defeat stress. TRPM2 which abundantly expressed in the CNS may play a critical role in maintaining behavioral flexibility and social avoidance induced by social defeat.

\section{Experimental Procedure}

\subsection{Animals}

Homozygous TRPM2-deficient mice [5] were backcrossed to C57BL/6 (SLC, Inc., Shizuoka, Japan; backcross number $=6$ ). All experiments except for repeated social defeat stress paradigm were performed using littermates of TRPM2-deficient and WT mice born from heterozygous mutant parents. All behavioral studies, including the learning and memory tests (see below), were performed between 9:00 A.M. and 5:00 P.M. using adult male mice that were at least 8 weeks of age. All experimental procedures were approved by the Kyoto University Animal Experimentation Committee.

\subsection{General behavioral studies}

To compare the physical characteristics of TRPM2-deficient mice and WT littermates, we first conducted neurological screening as previously described [39]. The righting, 
whisker touch, and ear twitch reflexes were evaluated, and physical measures including body weight, body temperature, and the presence of whiskers or bald patches were recorded. Neuromuscular strength was tested with the grip strength test and wire hang test. A grip strength meter (O'Hara \& Co., Tokyo, Japan) was used to assess forelimb grip strength. Mice were lifted and held by their tail so that their forepaws could grasp a wire grid. The mice were then gently pulled backward by the tail with their posture parallel to the surface of the table until they released the grid. The peak force applied by the forelimbs of the mouse was recorded in Newtons (N). Each mouse was tested three times, and the greatest value measured was used for statistical analysis. In the wire hang test, the mouse was placed on a wire mesh that was then inverted and waved gently, so that the mouse gripped the wire. Latency to fall was recorded, with a $60 \mathrm{sec}$ cut-off time.

\subsection{Light/dark transition test}

The apparatus used for the light/dark transition test consisted of a cage $(21 \times 42 \times 25$ cm) divided into two sections of equal size by a partition containing a door (O'Hara \& Co., Tokyo, Japan). One chamber was brightly illuminated (390 lux), whereas the other chamber was dark (2 lux). Mice were placed into the dark side and allowed to move freely between the two chambers with the door open for $10 \mathrm{~min}$. The total number of transitions between chambers, time spent in each side, first latency to enter the light side and distance travelled were recorded automatically using Image LD software (see 'Image analysis'). 


\subsection{Elevated plus maze test}

The elevated plus-maze (O'Hara \& Co., Tokyo, Japan) consisted of two open arms $(25 \times$ $5 \mathrm{~cm}$ ) and two enclosed arms of the same size, with $15-\mathrm{cm}$ high transparent walls. The arms and central square were made of white plastic plates and were elevated to a height of $55 \mathrm{~cm}$ above the floor. To minimize the likelihood of animals falling from the apparatus, 3-mm high plastic ledges were provided for the open arms. Arms of the same type were arranged at opposite sides to each other. Each mouse was placed in the central square of the maze $(5 \times 5 \mathrm{~cm})$, facing one of the closed arms. Mouse behavior was recorded during a 10 -min test period. The numbers of entries into, and the time spent in open and enclosed arms, were recorded. The illumination level was 100 lux at the center of the maze. For data analysis, we used the following four measures: the percentage of entries into the open arms, the time spent in the open arms (sec), the number of total entries, and total distance travelled $(\mathrm{cm})$. Data acquisition and analysis were performed automatically using Image EP software (see 'Image analysis').

\subsection{Social interaction test in a novel environment}

Two mice of identical genotypes that were previously housed in different cages were placed in a box together $(40 \mathrm{~cm} \times 40 \mathrm{~cm} \times 30 \mathrm{~cm})$ and allowed to explore freely for 10 min. Social behavior was monitored with a CCD camera connected to a Macintosh computer, and analysis was performed automatically using Image SI software (see Data Analysis). The total number of contacts, total duration of active contacts, total contact 
duration, mean duration per contact, and total distance traveled were measured. The active contact was defined as follows. Images were captured at 3 frames per second, and distance traveled between two successive frames was calculated for each mouse. If the two mice contacted each other and the distance traveled by either mouse was longer than $3 \mathrm{~cm}$, the behavior was considered an "active contact."

\subsection{Rotarod test}

Motor coordination and balance were tested with a rotarod test. The rotarod test, using an accelerating rotarod (UGO Basile Accelerating Rotarod, Varese, Italy), was performed by placing mice on rotating drums $(3 \mathrm{~cm}$ diameter $)$ and measuring the time each animal was able to maintain its balance on the rod. The speed of the rotarod accelerated from 4 to 40 rpm over a 5-min period.

\subsection{Open field test}

Locomotor activity was measured using an open field test. Each mouse was placed in the center of the open field apparatus $(40 \times 40 \times 30 \mathrm{~cm}$; Accuscan Instruments, Columbus, $\mathrm{OH}$ ). Total distance traveled, vertical activity (rearing measured by counting the number of photobeam interruptions), time spent in the center, the beam-break counts for stereotyped behaviors, and number of fecal boli were recorded. Data were collected for $120 \mathrm{~min}$.

\subsection{Porsolt forced swim test}


The apparatus for Porsolt forced swim test consisted of four plastic cylinders $(20 \mathrm{~cm}$ height $\times 10 \mathrm{~cm}$ diameter). The cylinders were filled with water (room temperature) up to a height of $7.5 \mathrm{~cm}$. Mice were placed into the cylinders, and their behavior were recorded over a 10-min test period. Images were captured at one frame per second. For each pair of successive frames, the amount of area (pixels) within which the mouse moved was measured. When the amount of area was below a certain threshold (i.e., 40 pixels), mouse behavior was judged as “immobile." When the amount of area equaled or exceeded the threshold, the mouse was considered to be "moving." The optimal threshold (amount of pixels) by which to judge immobility was determined by adjusting it to the amount of immobility measured by human observation. A capturing rate of one frame per second yielded results that were in good agreement with those obtained by human observation. Immobility lasting for less than a defined time threshold (i.e., $2 \mathrm{sec}$ ) was not included in the analysis. Distance traveled was measured by Image OF software (see Image analysis) using stored image files.

\subsection{Y-maze test}

Exploratory activity was measured using a Y-maze apparatus (arm length: $40 \mathrm{~cm}$, arm bottom width: $3 \mathrm{~cm}$, arm upper width: $10 \mathrm{~cm}$, height of wall: $12 \mathrm{~cm}$ ). Each mouse was placed in the center of the Y-maze field. The numbers of entries and alterations were recorded using a modified version of the Image EP program. Data were collected for 10 $\min$. 


\subsection{Barnes circular maze test}

The Barnes task was conducted on "dry land," a white circular surface, $1.0 \mathrm{~m}$ in diameter, with 12 holes equally spaced around the perimeter ( $\mathrm{O}^{\prime}$ Hara \& Co., Tokyo, Japan). The circular open field was elevated $75 \mathrm{~cm}$ from the floor. A black Plexiglas escape box $(17 \times 13 \times 7 \mathrm{~cm})$, which had paper cage bedding on its bottom, was located under one of the holes. The hole above the escape box represented the target, analogous to the hidden platform in the Morris task. The location of the target was consistent for a given mouse, but was randomized across mice. The maze was rotated daily, with the spatial location of the target unchanged with respect to the visual room cues, to prevent a bias based on olfactory or proximal cues within the maze. One day after the last training (trial 12), a probe trial was conducted without the escape box, to confirm that this spatial task was acquired based on navigation using distal environment room cues. Time of latency to reach the target hole, number of errors, distance to reach the target hole, and time spent around each hole were recorded by video tracking software (Image BM, see 'Image analysis'). A single training trial was conducted immediately after the probe test. An additional probe test (retention test) was conducted one week after the last training trial. Latency to reach the target hole and time spent around each hole were recorded by video tracking software (Image BM). One week after the memory retention test, the escape box was moved to a new position opposite to the original (reversal learning). Mice were then tested on five successive trials to locate the new position of the escape hole using the same procedure as described above. One day after the last training (trial 25), a probe trial was conducted. 


\subsection{Eight-arm radial maze test.}

The floor of the maze was made of white Plexiglas, and the wall $(16 \mathrm{~cm}$ high $)$ consisted of transparent Plexiglas. Each arm $(9 \times 3 \times 50 \mathrm{~cm})$ radiated from an octagonal central starting platform (perimeter $12 \times 3 \times 8 \mathrm{~cm}$ ) like the spokes of a wheel. Identical food wells (1.4 cm deep and $1.4 \mathrm{~cm}$ in diameter) with pellet sensors were placed at the distal end of each arm. The pellet sensors were able to automatically record pellet intake by the mice. The maze was elevated $35 \mathrm{~cm}$ above the floor and placed in a dimly lit room with several extra-maze cues. During the experiment, the maze was maintained in a constant orientation.

Before pretraining, animals were deprived of food until their body weight was reduced to $80-85 \%$ of the initial level. Each mouse was placed in the central starting platform and allowed to explore and to consume food pellets scattered on the whole maze for a 5 min period (one session per mouse). After completion of the initial pretraining, mice received another pretraining to take a pellet from each food well after being placed at the distal end of each arm. A trial was finished after the subject consumed the pellet. This was repeated eight times, using eight different arms, for each mouse.

After these pretraining trials, actual maze acquisition trials were performed. All eight arms were baited with food pellets. Mice were placed on the central platform and allowed to get all eight pellets within $15 \mathrm{~min}$. A trial was terminated immediately after all eight pellets were consumed or 15 min had elapsed. An "arm visit" was defined as traveling for $.5 \mathrm{~cm}$ from the central platform. The mice were confined in the center 
platform for $5 \mathrm{sec}$ after each arm choice. For each trial, choices of arms, latency to get all pellets, distance traveled, the number of different arms chosen within the first eight choices, and the number of revisiting and omission errors were automatically recorded. During the 17th acquisition trial, a $30 \mathrm{sec}$ delay was initiated after four pellets had been taken by confining the mice in the center platform. From the 19 th to the 20 th acquisition trial, the delay period was extended to $2 \mathrm{~min}$. From the $21 \mathrm{st}$ to the $22 \mathrm{nd}$ acquisition trial, the delay period was extended to $5 \mathrm{~min}$. After each trial, the maze was cleaned with water. The locations of the maze arms were randomly relocated after each session to prevent animals from using intra-maze cues. Data acquisition, control of guillotine doors, and data analysis were performed by Image RM software (see Image analysis).

\subsection{Tail suspension test}

Mice were suspended $30 \mathrm{~cm}$ above the floor in a visually isolated area by adhesive tape placed $\sim 1 \mathrm{~cm}$ from the tip of the tail. The duration of immobility was recorded over a 10-min test period. Images were captured as described in Porsolt forced swim test section. Data acquisition and analysis were performed automatically using Image TS software (see Image Analysis below).

\subsection{T-maze}

The forced alternation test was conducted as previously described [40]. The maze was constructed of white plastics runways with walls $25-\mathrm{cm}$ high and partitioned into the right and left arms $(11.5 \times 20.5 \mathrm{~cm})$ and the stem $(13 \times 24 \mathrm{~cm})$ area by automated 
sliding doors. The end of each arm was equipped with a food dispenser that was able to provide a food reward. The pellet sensors were able to automatically record the pellet intake by the mice. After making their arm choice, the mice were able to return to the starting compartment, namely the stem of the T-maze, through a runway. A variety of fixed extra-maze clues surrounded the apparatus.

The mice were kept on a maintenance diet as described above. After dieting, all mice underwent 3 days of habituation to the apparatus and received rewards (10 min of exposure to the maze each day, with rewards placed at both ends of the T-maze). On the first (sample) run of each trial, both goal arms were baited, but the mouse was forced to choose one of the goal arms (the other being blocked by a removable door). After entering the preselected goal arm, the mouse was allowed 20 seconds to consume the reward and then could go back to the start box. During the second run (choice), both goal arms were open and the mouse was rewarded for choosing the previously unvisited arm. The location of the sample arm (left or right) was varied pseudorandomly across trials so that the mice received equal numbers of left and right presentations, but no more than two consecutive trials had the same sample location. These training sessions were continued for 10 trials. To set higher demands on working memory, intratrial intervals between two runs (sample and choice) were set at 10, 30 and 60 seconds. Next, the mice were tested for Left-Right discrimination in the T-maze [41]. The mice were placed in the stem of the T-maze. The door leading to the straight alley was opened and the mice were able to freely choose either the right or left arm of the T-maze. If a mouse chose the baited (correct) arm, it was allowed to consume the food reward. The 
mouse was then allowed to return to the starting compartment. The correct arm was assigned to each mouse randomly. On trial 11 , the correct arm was changed to test reversal learning.

\subsection{Image analysis}

The applications used for the behavioral studies (Image LD, Image EP, Image BM, Image RM, and Image TM, Image TS) were based on the public domain NIH Image program (developed at the U.S. National Institutes of Health and available on the Internet at http://rsb.info.nih.gov/nih-image/) and ImageJ program http://rsb.info.nih.gov/ij/, which were modified for each test by Miyakawa (available through O'Hara \& Co., Tokyo, Japan).

\subsection{Repeated social defeat stress}

Repeated social defeat stress was applied as described previously [15] with minor modifications. Briefly, ICR mice were screened based on their aggressiveness to a naïve $\mathrm{C} 57 \mathrm{BL} / 6$ mouse, as measured by the latency and the number of attacks, and were used as aggressor mice for repeated social defeat stress. Before the beginning of repeated social defeat, the 7-week-old male homozygous TRPM2-deficient mice (backcrossed to $\mathrm{C} 57 \mathrm{BL} / 6$, backcross number $=10)$ and WT mice to be defeated were isolated for 1 week. Food and water were available ad libitum. For repeated social defeat, an isolated mouse to be defeated was introduced and kept in the homecage of a resident aggressor ICR mouse for 5 min daily for 10 consecutive days. The pair of defeated and aggressor 
mice was changed daily to minimize the variability in the aggressiveness of ICR. The social interaction test was performed at the next day of final defeat session as described below. The social interaction test was performed as described previously [15] with minor modifications. Individually housed mice were acclimated to testing rooms under the red dim light for at least $30 \mathrm{~min}$ before the test. First, for habituation to a test environment, a defeated mouse was kept for $150 \mathrm{sec}$ in an open field chamber $(50 \times 50$ $\times 50 \mathrm{~cm})$ with an empty wire mesh cage $(10 \times 6.5 \mathrm{~cm})$ located at one end of the field. Consecutively, the same mouse was kept for $150 \mathrm{sec}$ in the same open field chamber with an unfamiliar ICR mouse enclosed in the wire mesh cage. Mouse behaviors were video monitored, and the trajectory of mouse ambulation was determined and recorded by ANY-MAZE (Stoelting Co., Wood Dale, IL, USA). The four corners of the chamber ( $9 \mathrm{~cm}$ square) defined as the avoidance zone and the area surrounding the wire mesh cage $(14 \times 24 \mathrm{~cm})$ defined as the interaction zone. Interaction ratio was calculated as time spent in the interaction zone in the presence of an unfamiliar ICR mouse divided by that in the absence of ICR mouse. The proportion of time spent in the interaction and avoidance zones during the observation period $(150 \mathrm{sec})$ and interaction ratio was used as an index for the level of social avoidance. After repeated social defeat, the elevated plus maze test was performed using another batch of mice. The apparatus was consisted of two open arms and two closed arms $(30 \times 5 \mathrm{~cm})$ extended from a central platform $(5$ $\times 5 \mathrm{~cm}$ ). Each animal was placed individually into the central platform, facing one of the open arms. The behavior of the animal was recorded with a camera over a $10 \mathrm{~min}$ session; the recorded data were analyzed automatically using video tracking system 
(ANY-maze version 4.99, Stoelting Co.). Time spent in the open arm and the closed arm during a session were measured. Percentage of the time spent in the open arm was calculated as following; $100 \times$ open arm time (s) / (open arm time (s) + closed arm time (s) ).

\subsection{Measurement of serum corticosterone level}

Measurement of serum corticosterone level was performed as described previously [42] with slight modification. Mice after repeated social defeat stress or naive mice were decapitated, and trunk blood was collected. Collected blood was directly used for the extraction of corticosterone. Determination of corticosterone concentration was performed with corticosterone EIA kit (\#501320, Cayman Chemical, Ann Arbor, MI, USA) as manufacture's instruction.

\subsection{Statistical analysis}

Statistical analysis was conducted using Graphpad Prism 7 (GraphPad, San Diego, CA, USA; repeated social defeat stress) or Stat View (SAS institute, Cary, NC, USA; other tests). Data were analyzed by two-way ANOVA, or two-way repeated measures ANOVA, unless noted otherwise. Values in text and graphs were expressed as mean \pm SEM. All $\mathrm{p}$-values reported are two tailed. Statistical significance was defined as $\mathrm{p}<.05$.

\section{Funding}

This work was supported by Grant-in-Aid for Scientific Research from Japan Society 
for the Promotion of Science (to K.N. (16K15125), H.S. (17K19486), T.N. (17H04008), and S.K. (16H05091)), and Research Grant from Takeda Science Foundation (to K.N.).

\section{Acknowledgement}

We thank Drs. T. Furuyashiki, S. Kitaoka, and R. Shinohara (Kobe University, Japan) for critical help in repeated social defeat experiment. We thank Drs. H. Hashimoto, and A. Kasai (Osaka University, Japan) for critical help in measuring serum corticosterone.

Declarations of Interest: none 


\section{References}

[1] A.L. Perraud, A. Fleig, C.A. Dunn, L.A. Bagley, P. Launay, C. Schmitz, A.J. Stokes, Q. Zhu, M.J. Bessman, R. Penner, J.P. Kinet, A.M. Scharenberg, ADP-ribose gating of the calcium-permeable LTRPC2 channel revealed by Nudix motif homology, Nature. 411 (2001) 595-599. doi:10.1038/35079100.

[2] Y. Hara, M. Wakamori, M. Ishii, E. Maeno, M. Nishida, T. Yoshida, H. Yamada, S. Shimizu, E. Mori, J. Kudoh, N. Shimizu, H. Kurose, Y. Okada, K. Imoto, Y. Mori, LTRPC2 Ca2+-Permeable Channel Activated by Changes in Redox Status Confers Susceptibility to Cell Death, 9 (2002) 163-173. doi.org/10.1016/S1097-2765(01)00438.

[3] K. Togashi, Y. Hara, T. Tominaga, T. Higashi, Y. Konishi, Y. Mori, M. Tominaga, TRPM2 activation by cyclic ADP-ribose at body temperature is involved in insulin secretion, EMBO J. 25 (2006) 1804-1815. doi:10.1038/sj.emboj.7601083.

[4] K. Uchida, K. Dezaki, B. Damdindorj, H. Inada, T. Shiuchi, Y. Mori, T. Yada, Y. Minokoshi, M. Tominaga, Lack of TRPM2 impaired insulin secretion and glucose metabolisms in mice, Diabetes. 60 (2011) 119-126. doi:10.2337/db10-0276.

[5] S. Yamamoto, S. Shimizu, S. Kiyonaka, N. Takahashi, T. Wajima, Y. Hara, T. Negoro, T. Hiroi, Y. Kiuchi, T. Okada, S. Kaneko, I. Lange, A. Fleig, R. Penner, M. Nishi, H. Takeshima, Y. Mori, TRPM2-mediated Ca2+ influx induces chemokine production in monocytes that aggravates inflammatory neutrophil infiltration, Nat. Med. 14 (2008) 738-747. doi:10.1038/nm1758.

[6] K. Nagamine, J. Kudoh, S. Minoshima, K. Kawasaki, S. Asakawa, F. Ito, N. 
Shimizu, Molecular Cloning of a Novel Putative Ca2+Channel Protein (TRPC7) Highly Expressed in Brain, Genomics. 54 (1998) 124-131. doi:10.1006/geno.1998.5551.

[7] I.S. Yoon, P.P. Li, K.P. Siu, J.L. Kennedy, F. Macciardi, R.G. Cooke, S. V. Parikh, J.J. Warsh, Altered TRPC7 gene expression in bipolar-I disorder, Biol. Psychiatry. 50 (2001) 620-626. doi:10.1016/S0006-3223(01)01077-0.

[8] C. Xu, F. Macciardi, P.P. Li, I.S. Yoon, R.G. Cooke, B. Hughes, S. V. Parikh, R.S. McIntyre, J.L. Kennedy, J.J. Warsh, Association of the putative susceptibility gene, transient receptor potential protein melastatin type 2, with bipolar disorder, Am. J. Med. Genet. - Neuropsychiatr. Genet. 141 B (2006) 36-43. doi:10.1002/ajmg.b.30239.

[9] C. Xu, P.P. Li, R.G. Cooke, S. V. Parikh, K.S. Wang, J.L. Kennedy, J.J. Warsh, TRPM2 variants and bipolar disorder risk: Confirmation in a family-based association study, Bipolar Disord. 11 (2009) 1-10. doi:10.1111/j.1399-5618.2008.00655.x.

[10]R. Kraft, C. Grimm, K. Grosse, A. Hoffmann, S. Sauerbruch, H. Kettenmann, G. Schultz, C. Harteneck, Hydrogen peroxide and ADP-ribose induce TRPM2-mediated calcium influx and cation currents in microglia., Am. J. Physiol. Cell Physiol. 286 (2004) C129-37. doi:10.1152/ajpcell.00331.2003.

[11] S. Kaneko, S. Kawakami, Y. Hara, M. Wakamori, E. Itoh, T. Minami, Y. Takada, T. Kume, H. Katsuki, Y. Mori, A. Akaike, A critical role of TRPM2 in neuronal cell death by hydrogen peroxide, J Pharmacol Sci. 101 (2006) 66-76. 
doi:JST.JSTAGE/jphs/FP0060128.

[12] M.E. Olah, M.F. Jackson, H. Li, Y. Perez, H.-S. Sun, S. Kiyonaka, Y. Mori, M. Tymianski, J.F. MacDonald, Ca2+-dependent induction of TRPM2 currents in hippocampal neurons, J. Physiol. 587 (2009) 965-979. doi:10.1113/jphysiol.2008.162289.

[13] K.K.H. Chung, P.S. Freestone, J. Lipski, Expression and functional properties of TRPM2 channels in dopaminergic neurons of the substantia nigra of the rat, J. Neurophysiol. 106 (2011) 2865-75. doi:10.1152/jn.00994.2010.

[14] Y.-F. Xie, J.C. Belrose, G. Lei, M. Tymianski, Y. Mori, J.F. MacDonald, M.F. Jackson, Dependence of NMDA/GSK-3ßMediated Metaplasticity on TRPM2 Channels at Hippocampal CA3-CA1 Synapses, Mol. Brain. 4 (2011) 44. doi:10.1186/1756-6606-4-44.

[15] S.A. Golden, H.E. Covington, O. Berton, S.J. Russo, A standardized protocol for repeated social defeat stress in mice, Nat. Protoc. 6 (2011) 1183-1191. doi:10.1038/nprot.2011.361.

[16]K. Fabricius, G. Wörtwein, B. Pakkenberg, The impact of maternal separation on adult mouse behaviour and on the total neuron number in the mouse hippocampus, Brain Struct. Funct. 212 (2008) 403-416. doi:10.1007/s00429-007-0169-6.

[17]LD. Devenport, RL. Hale, JA. Stidham, Sampling behavior in the radial maze and operant chamber: role of the hippocampus and prefrontal area. Behav. Neurosci. 102 (1988) 4894-4898.

[18] T. Uemura, J. Kudoh, S. Noda, S. Kanba, N. Shimizu, Characterization of human 
and mouse TRPM2 genes: Identification of a novel N-terminal truncated protein specifically expressed in human striatum, Biochem. Biophys. Res. Commun. 328 (2005) 1232-1243. doi:10.1016/j.bbrc.2005.01.086.

[19] J.Z. Bai, J. Lipski, Differential expression of TRPM2 and TRPV4 channels and their potential role in oxidative stress-induced cell death in organotypic hippocampal culture, Neurotoxicology. 31 (2010) 204-214. doi:10.1016/j.neuro.2010.01.001.

[20] M. Watanabe, T. Kodama, K. Hikosaka, Increase of extracellular dopamine in primate prefrontal cortex during a working memory task, J. Neurophysiol. 78 (1997) 2795-2798. doi:10.1002/SYN.10038.

[21] M.D. Hauser, Perseveration, inhibition and the prefrontal cortex: A new look, Curr. Opin. Neurobiol. 9 (1999) 214-222. doi:10.1016/S0959-4388(99)80030-0.

[22]K. Schwabe, T. Enkel, S. Klein, M. Schütte, M. Koch, Effects of neonatal lesions of the medial prefrontal cortex on adult rat behaviour, Behav. Brain Res. 153 (2004) 21-34. doi:10.1016/j.bbr.2003.10.030.

[23]J. Zahrt, J.R. Taylor, R.G. Mathew, A.F. Arnsten, Supranormal stimulation of D1 dopamine receptors in the rodent prefrontal cortex impairs spatial working memory performance, J Neurosci. 17 (1997) 8528-35.

[24] S.B. Glickstein, P.R. Hof, C. Schmauss, Mice lacking dopamine D2 and D3 receptors have spatial working memory deficits, J. Neurosci. 22 (2002) 5619-29.

[25]C. Kellendonk, E.H. Simpson, H.J. Polan, G. Malleret, S. Vronskaya, V. Winiger, H. Moore, E.R. Kandel, Transient and selective overexpression of dopamine D2 
receptors in the striatum causes persistent abnormalities in prefrontal cortex functioning, Neuron. 49 (2006) 603-615. doi:10.1016/j.neuron.2006.01.023.

[26] A. Mrejeru, A. Wei, J.M. Ramirez, Calcium-activated non-selective cation currents are involved in generation of tonic and bursting activity in dopamine neurons of the substantia nigra pars compacta, J. Physiol. 589 (2011) 2497-2514. doi:10.1113/jphysiol.2011.206631.

[27] A. Kamsler, M. Segal, Hydrogen peroxide modulation of synaptic plasticity, J. Neurosci. 23 (2003) 269-276.

[28] A. Kamsler, M. Segal, Paradoxical actions of hydrogen peroxide on long-term potentiation in transgenic superoxide dismutase-1 mice, J. Neurosci. 23 (2003) 10359-10367.

[29] J.B. Watson, M.M. Arnold, Y.-S. Ho, T.J. O’Dell, Age-dependent modulation of hippocampal long-term potentiation by antioxidant enzymes, J. Neurosci. Res. 84 (2006) 1564-1574. doi:10.1002/jnr.21040.

[30] S. Duffy, V. Labrie, J.C. Roder, D -Serine Augments NMDA-NR2B

Receptor-Dependent Hippocampal Long-Term Depression and Spatial Reversal Learning, 1 (2008) 1004-1018. doi:10.1038/sj.npp.1301486.

[31]H. Zeng, S. Chattarji, M. Barbarosie, L. Rondi-Reig, B.D. Philpot, T. Miyakawa, M.F. Bear, S. Tonegawa, Forebrain-specific calcineurin knockout selectively impairs bidirectional synaptic plasticity and working/episodic-like memory, Cell. 107 (2001) 617-629. doi:10.1016/S0092-8674(01)00585-2.

[32] M. Maes, P. Galecki, Y.S. Chang, M. Berk, A review on the oxidative and 
nitrosative stress (O\&NS) pathways in major depression and their possible contribution to the (neuro)degenerative processes in that illness, Prog. Neuro-Psychopharmacology Biol. Psychiatry. 35 (2011) 676-692. doi:10.1016/j.pnpbp.2010.05.004.

[33] M. Ibi, J. Liu, N. Arakawa, S. Kitaoka, A. Kawaji, K. Matsuda, K. Iwata, M. Matsumoto, M. Katsuyama, K. Zhu, S. Teramukai, T. Furuyashiki, C. Yabe-Nishimura, Depressive-Like Behaviors Are Regulated by NOX1/NADPH Oxidase by Redox Modification of NMDA Receptor 1, J. Neurosci. 37 (2017) 4200-4212. doi:10.1523/JNEUROSCI.2988-16.2017.

[34] J.-S. Seo, J.-Y. Park, J. Choi, T.-K. Kim, J.-H. Shin, J.-K. Lee, P.-L. Han, NADPH Oxidase Mediates Depressive Behavior Induced by Chronic Stress in Mice, J. Neurosci. 32 (2012) 9690-9699. doi:10.1523/JNEUROSCI.0794-12.2012.

[35] V. Krishnan, M.H. Han, D.L. Graham, O. Berton, W. Renthal, S.J. Russo, Q. LaPlant, A. Graham, M. Lutter, D.C. Lagace, S. Ghose, R. Reister, P. Tannous, T.A. Green, R.L. Neve, S. Chakravarty, A. Kumar, A.J. Eisch, D.W. Self, F.S. Lee, C.A. Tamminga, D.C. Cooper, H.K. Gershenfeld, E.J. Nestler, Molecular Adaptations Underlying Susceptibility and Resistance to Social Defeat in Brain Reward Regions, Cell. 131 (2007) 391-404. doi:10.1016/j.cell.2007.09.018.

[36] C. Challis, J. Boulden, A. Veerakumar, J. Espallergues, F.M. Vassoler, R.C. Pierce, S.G. Beck, O. Berton, Raphe GABAergic neurons mediate the acquisition of avoidance after social defeat, J. Neurosci. 33 (2013) 13978-13988. doi:10.1523/JNEUROSCI.2383-13.2013. 
[37] D. Chaudhury, J.J. Walsh, A.K. Friedman, B. Juarez, S.M. Ku, J.W. Koo, D. Ferguson, H.C. Tsai, L. Pomeranz, D.J. Christoffel, A.R. Nectow, M. Ekstrand, A. Domingos, M.S. Mazei-Robison, E. Mouzon, M.K. Lobo, R.L. Neve, J.M. Friedman, S.J. Russo, K. Deisseroth, E.J. Nestler, M.H. Han, Rapid regulation of depression-related behaviours by control of midbrain dopamine neurons, Nature. 493 (2013) 532-536. doi:10.1038/nature11713.

[38] B.D. Sachs, J.R. Ni, M.G. Caron, Brain 5-HT deficiency increases stress vulnerability and impairs antidepressant responses following psychosocial stress, Proc. Natl. Acad. Sci. 112 (2015) 201416866. doi:10.1073/pnas.1416866112.

[39] T. Miyakawa, M. Yamada, A. Duttaroy, J. Wess, Hyperactivity and intact hippocampus-dependent learning in mice lacking the M1 muscarinic acetylcholine receptor, J. Neurosci. 21 (2001) 5239-5250.

[40] K. Takao, K. Toyama, K. Nakanishi, S. Hattori, H. Takamura, M. Takeda, T. Miyakawa, R. Hashimoto, Impaired long-term memory retention and working memory in sdy mutant mice with a deletion in Dtnbp1, a susceptibility gene for schizophrenia, Mol. Brain. 1 (2008) 11. doi:10.1186/1756-6606-1-11.

[41]M. Ikeda, T. Hikita, S. Taya, J. Uraguchi-asaki, K. Toyo-Oka, A. Wynshaw-boris, H. Ujike, T. Inada, K. Takao, T.T. Miyakawa, N. Ozaki, K. Kaibuchi, N. Iwata, Identification of YWHAE, a gene encoding 14-3-3epsilon, as a possible susceptibility gene for schizophrenia, Hum. Mol. Genet. 17 (2008) 3212-3222. doi:10.1093/hmg/ddn217.

[42]K. Hazama, A. Hayata-Takano, K. Uetsuki, A. Kasai, N. Encho, N. Shintani, K. 
Nagayasu, R. Hashimoto, D. Reglodi, T. Miyakawa, T. Nakazawa, A. Baba, H.

Hashimoto, Increased behavioral and neuronal responses to a hallucinogenic drug in PACAP heterozygous mutant mice, PLoS One. 9 (2014) e89153. doi:10.1371/journal.pone.0089153

[43] X. Nie, S. Kitaoka, K. Tanaka, E. Segi-Nishida, Y. Imoto, A. Ogawa, F. Nakano, A. Tomohiro, K. Nakayama, M. Taniguchi, Y. Mimori-Kiyosue, A. Kakizuka, S. Narumiya, T. Furuyashiki, The innate immune receptors TLR2/4 mediate repeated social defeat stress-induced social avoidance through prefrontal microglial activation, Neuron. 99 (2018) 464-479. doi: 10.1016/j.neuron.2018.06.035.

[44]J. Miyanohara, M. Kakae, K. Nagayasu, T. Nakagawa, Y. Mori, K. Arai, H. Shirakawa, S. Kaneko, TRPM2 channel aggravates CNS inflammation and cognitive impairment via activation of microglia in chronic cerebral hypoperfusion, J. Neurosci. 38 (2018) 3520-3533. doi: 0.1523/JNEUROSCI.2451-17.2018. 


\section{Figure legends}

Figure 1. General characteristics and locomotor activity of TRPM2-deficient mice.

(A) Body weight, rectal temperature, grip strength, and wire hang did not differ between TRPM2-deficient mice $(n=20)$ and WT littermates $(n=20)$. (B) Total distance, vertical activity, center time, and stereotypic counts in the open field test were recorded.

Locomotor activity of TRPM2-deficient mice $(n=20)$ was similar to that of WT mice $(n$ $=20)$.

Figure 2. Working memory measured by eight-arm radial maze.

Different arm choices in the first eight entries (A), number of revisiting errors (B), and latency to visit all eight arms (C) are presented as the average of two trials. The first 16 trials were non-delay trials (5-sec lag before opening doors), followed by trials with a delay $(30,120$, or $300 \mathrm{sec}$, two trials each, D). There was no difference between TRPM2-deficient mice $(\mathrm{n}=17)$ and WT mice $(\mathrm{n}=19)$.

\section{Figure 3. Impaired behavioral flexibility in Barnes circular maze.}

Following 12 training sessions, the probe test was conducted twice. A 1 week retention period was added between the two probe tests to examine long-term memory retention. Mice were then trained again to remind them of the correct position. Trials $20-25$ were reverse trials in which the escape box was moved to the opposite side of the field, followed by a third probe test. The distance traveled (A), latency (B) and error number (C) before reaching the correct target of each trial (except for probe tests) were 
measured. Differences between the TRPM2-deficient $(n=20)$ and WT $(n=20)$ groups are indicated by an asterisk (two-way ANOVA, Bonferroni post-test, $* p<.05$ ). In probe tests, the time spent around all 12 holes was measured (D-F). ${ }^{*} \mathrm{p}<.05$.

Figure 4. Impaired behavioral flexibility in the T-maze forced alternation task. Latency to finishing the set of 10 choices (A) and the percentage of correct choices made (B) were recorded in the first 10 non-delay trials. The working memory of TRPM2-deficient mice $(\mathrm{n}=16)$ deteriorated compared with WT mice $(\mathrm{n}=13)$ when a delay was applied (C). ${ }^{*} \mathrm{p}<.05$.

\section{Figure 5. Normal spatial memory in the T-maze left/right discrimination task.}

Spatial reference memory of TRPM2-deficient mice $(n=16)$ and WT mice $(n=13)$ was measured in the T-maze left/right discrimination task. Trials 1-10 are normal trials and trials 11-18 are reverse trials in which the correct choice is moved to the opposite side. Percentage of correct choices made (A), latency to finish one trial (comprised of a set of 10 choices) (B), and distance traveled during one trial (C) were recorded.

\section{Figure 6. TRPM2-deficient mice are resilient to repeated social defeat stress.}

Stress resiliency of TRPM2-deficient mice $(n=28)$ and WT mice $(n=28)$ was examined in repeated social defeat paradigm. (A) Representative heat map of open field occupancy. Time in interaction zone (B) and time in avoidance zone (C) in the presence of a target ICR mouse was measured. Interaction ratio (D) was calculated as described 
in Materials and Methods. ${ }^{*} \mathrm{p}<.05,{ }^{*} \mathrm{p}<.01 \mathrm{vs.} \mathrm{WT} \mathrm{group} \mathrm{by} \mathrm{unpaired} t$-test. (E) Serum corticosterone levels were measured by EIA. $\mathrm{n}=12$ (WT-naive), 6 (WT-CSDS), 9 (TRPM2-deficient-naive), 7 (TRPM2-deficient-CSDS). (F) After repeated social defeat, WT and TRPM2-deficient mice were analyzed by the elevated plus maze test. Percentage of the spent time in the open arm in the elevated plus maze test was calculated as described in Materials and Methods. $\mathrm{n}=13$ (WT), 14 (TRPM2-deficient). 


\section{Figures}

Figure 1

A
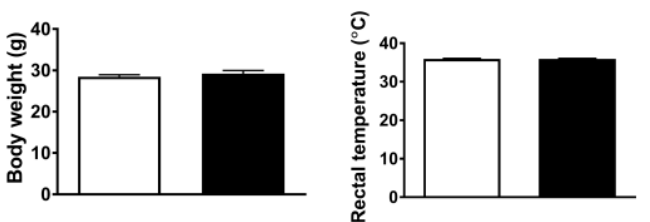

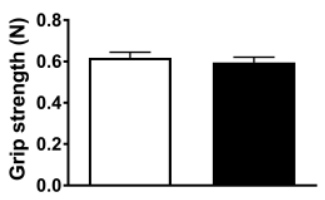

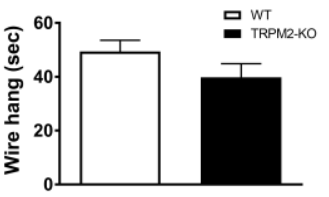

B
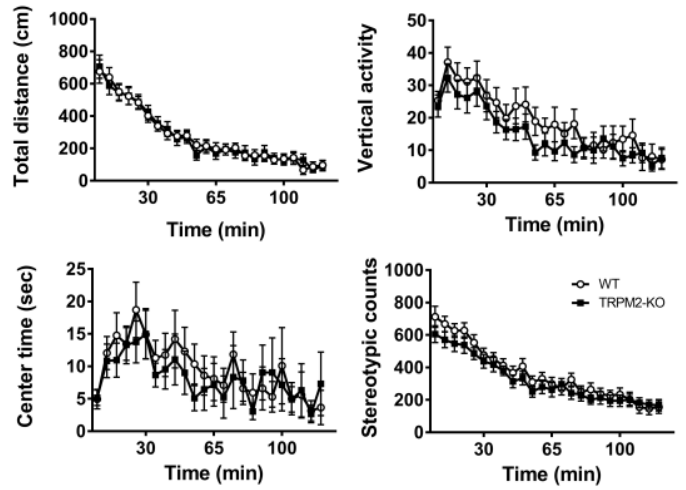
Figure 2

A

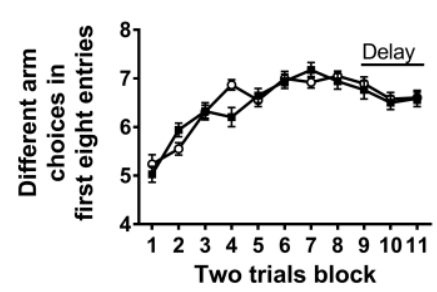

D

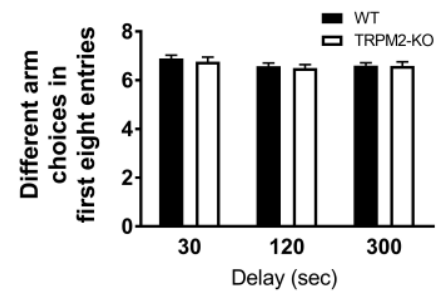

B
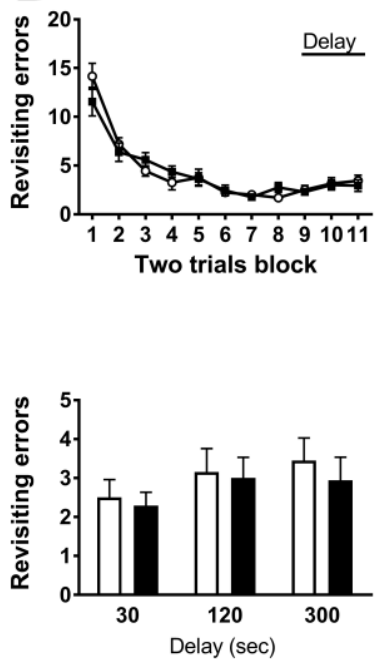

C
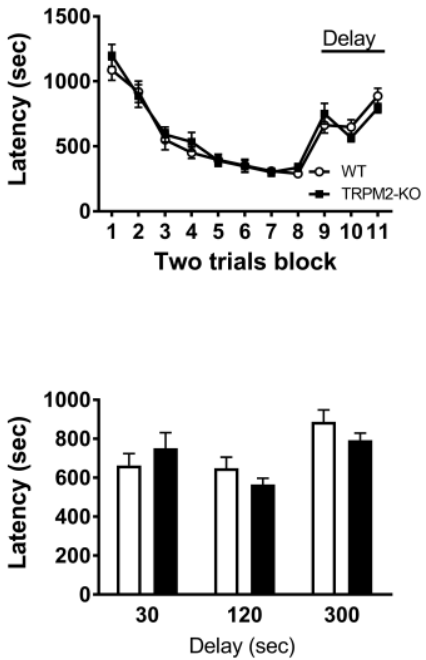


\section{Figure 3}
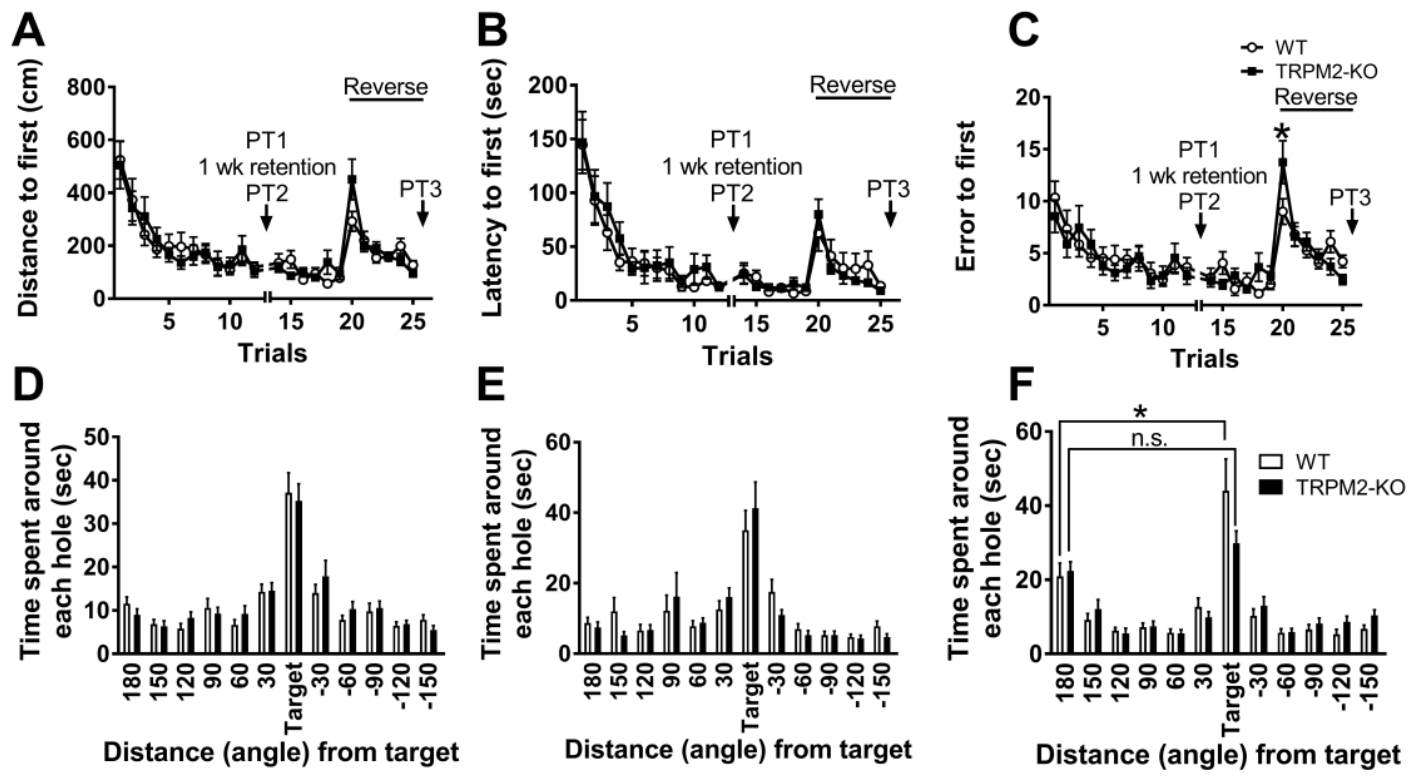


\section{Figure 4}
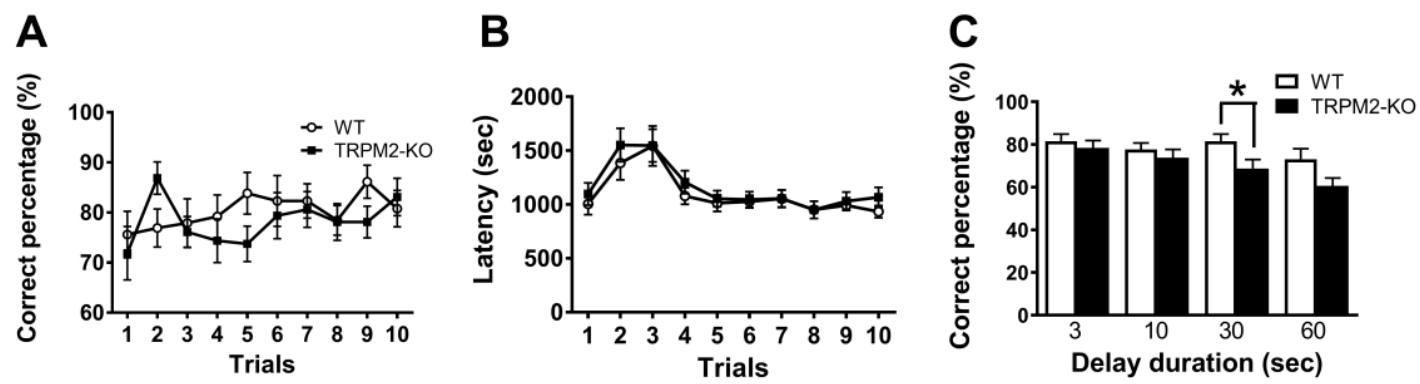


\section{Figure 5}
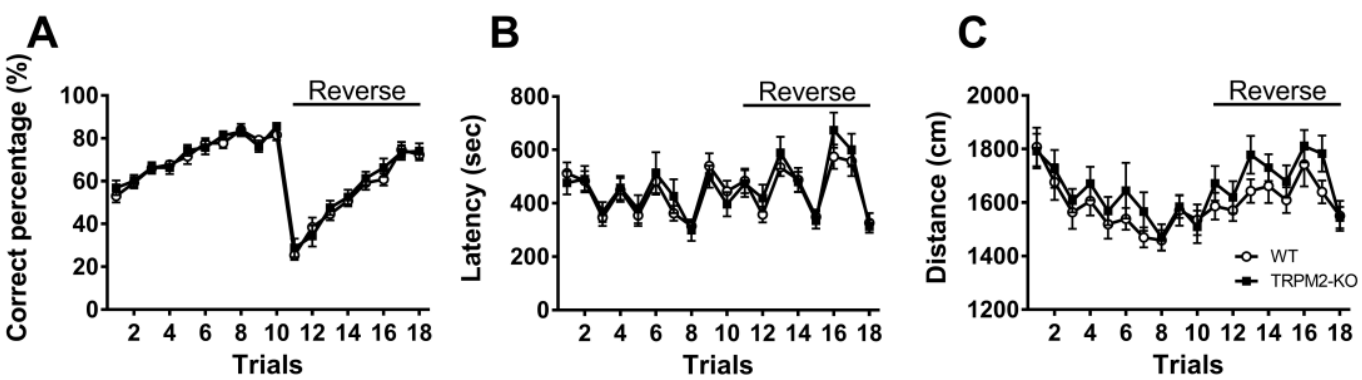
Figure 6

A

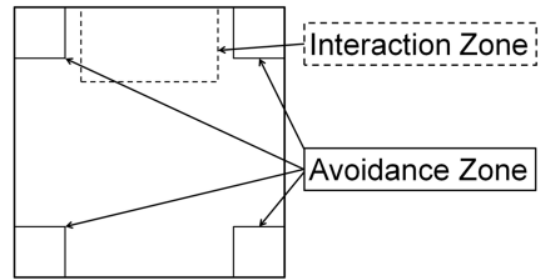

B

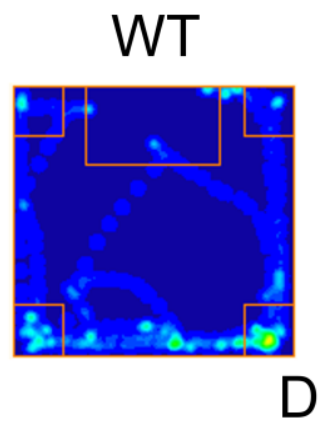

TRPM2-KO
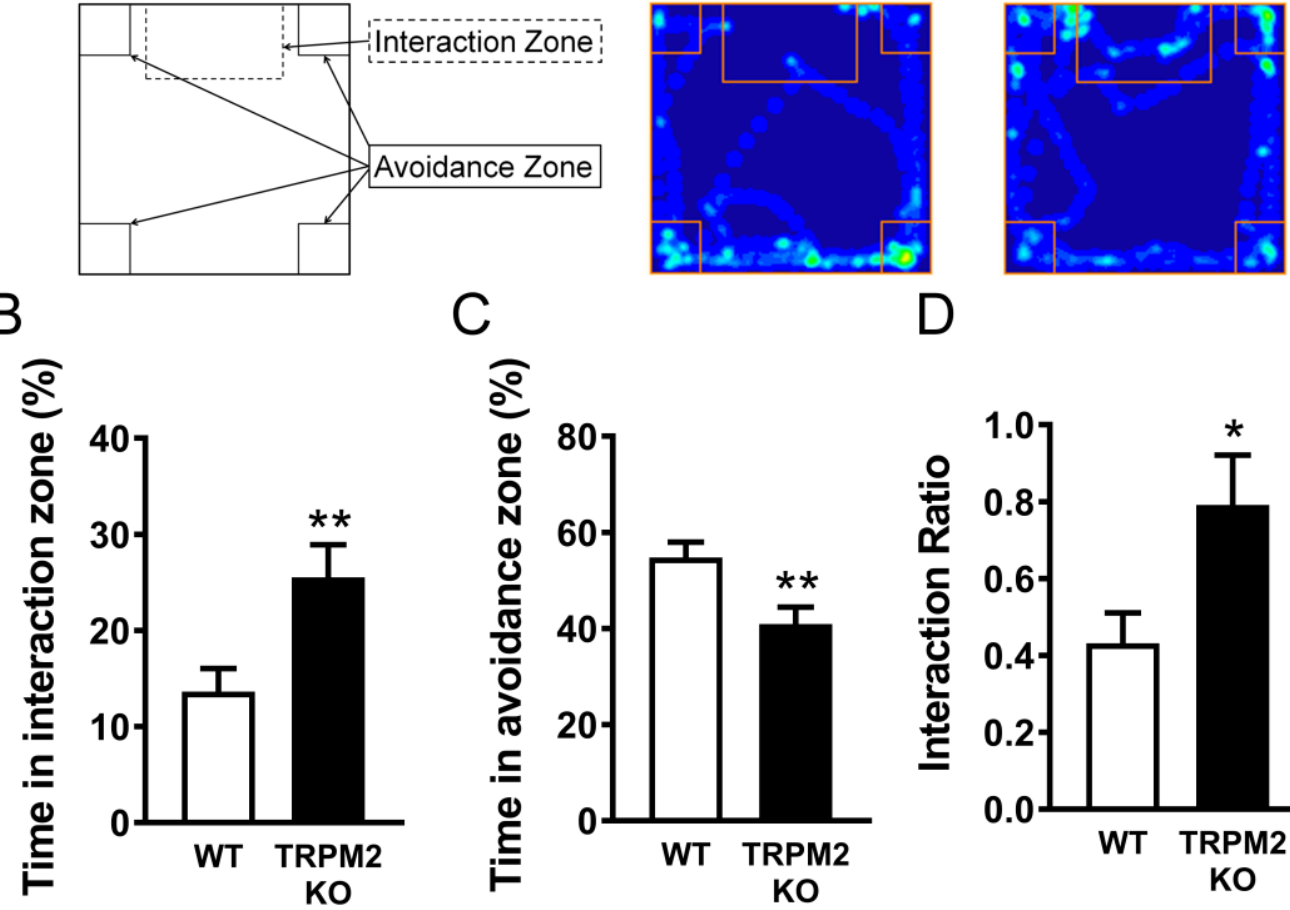

C

D
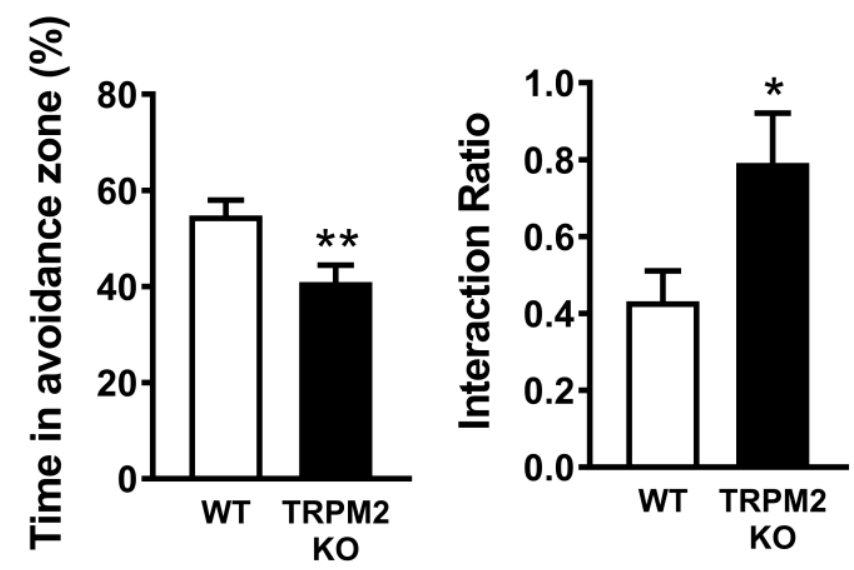

E

F
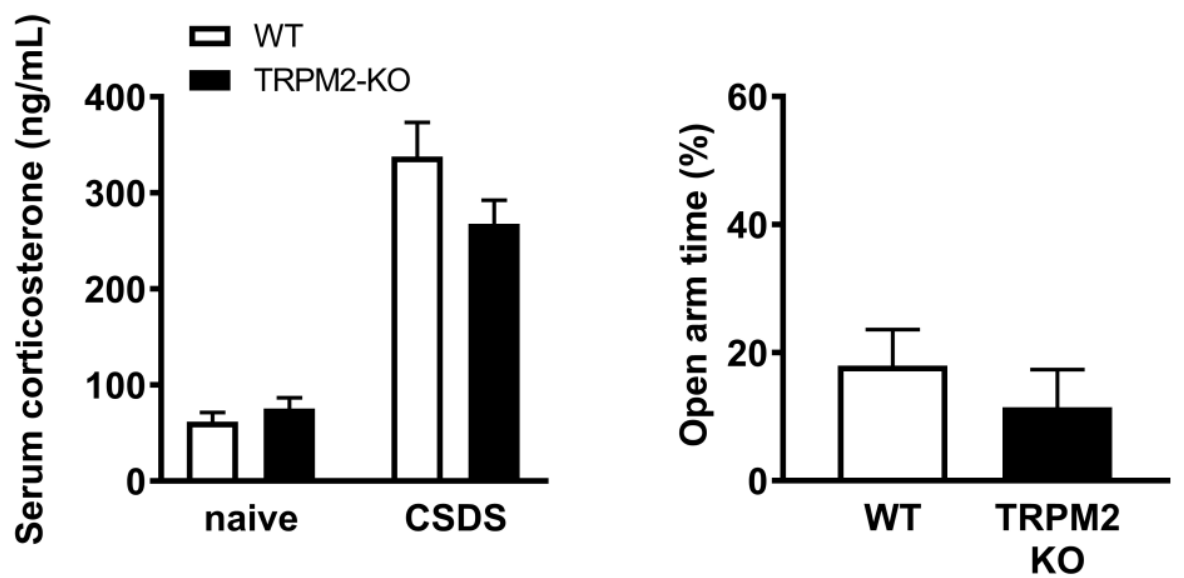
Table 1. Behavioral phenotypic comparison between TRPM2-deficient and WT

mice

Test

Control

Mutant

Statistics

p-value

Light-dark transition test $(n=20)$

Total distance in light $(\mathrm{cm})$

Total distance in dark $(\mathrm{cm})$

Stay time in light (sec)

Transition (times)

Latency to light (sec)
$1242 \pm 56.73$

$1219 \pm 66.50$

$t(38)=0.262$

.7947
$172.8 \pm 16.21$

$\mathrm{t}(38)=0.122$

9032
$578.4 \pm 58.46$

$t(38)=0.240$

8115

sec)

$24.75 \pm 1.665$

$22.50 \pm 1.954$

$t(38)=0.876$

.3863 
Rotarod $(n=20)$

Latency to fall (sec)

Elevated plus maze $(\mathrm{n}=20)$

Number of entries (times)

Entries into open arms (\%)

Total distance $(\mathrm{cm})$

Time in open arms (sec)

Total duration of contact (s)

Number of contacts (times)

Social interaction $(\mathrm{n}=10)$

\section{r}

$167.7 \pm 10.21$

$162.4 \pm 12.56$

$t(38)=0.3264$

7459

$29.9 \pm 2.08$

$24.8 \pm 2.71$

$\mathrm{t}(38)=1.495$

.1432

$11.75 \pm 1.669$

$13.06 \pm 2.241$

$t(38)=0.469$

.6419

$1571 \pm 92.23$

$1354 \pm 95.02$

$t(38)=1.635$

.1102

$2.1 \pm 0.5304$

$2.615 \pm 1.092$

$t(38)=0.6738$

.6738

$72.50 \pm 6.152$

$68.62 \pm 3.674$

$t(18)=0.5415$

.5948 
Total duration of active contacts (sec)

Mean duration of contact (sec)

Distance traveled $(\mathrm{cm})$

Prepulse inhibition

$\left(\mathrm{TRPM}^{-/-} \mathrm{n}=17\right.$, wt $\left.\mathrm{n}=19\right)$

74-110 dB (\%)

$78-110 \mathrm{~dB}(\%)$

74-120 dB (\%)

$78-120 \mathrm{~dB}(\%)$
$35.12 \pm 7.256$

$35.39 \pm 7.008$

$\mathrm{t}(34)=0.0260$

.9794

$53.95 \pm 6.943$

$47.39 \pm 6.498$

$t(34)=0.6855$

.4976

$23.12 \pm 5.831$

$26.27 \pm 7.642$

$\mathrm{t}(34)=0.3316$

.7423

Y-maze $(\mathrm{n}=20)$
$36.39 \pm 5.917 \quad 28.20 \pm 8.300 \quad \mathrm{t}(34)=0.8161$

.4201 
Number of entries (times)

Total alternations (times)

Alternation (times)

Total distance $(\mathrm{cm})$

Number of choices (times)

Immobility day $1(\%)$

Distance traveled on day $1(\mathrm{~cm})$

Immobility on day $2(\%)$

Distance traveled on day $2(\mathrm{~cm})$
$23.90 \pm 1.609$

$24.70 \pm 1.651$

$\mathrm{t}(38)=0.347$

.7305

$13.25 \pm 0.9202$

$14.65 \pm 1.308$

$\mathrm{t}(38)=0.8752$

.3870

$64.11 \pm 1.806$

$67.98 \pm 2.911$

$t(38)=1.13$

.2657

Porsolt forced swim test $(n=20)$

$2445 \pm 158.5$

$2516 \pm 157.4$

$\mathrm{t}(38)=0.3177$

.7524

$20.95 \pm 1.540$

$22.11 \pm 1.710$

$\mathrm{t}(38)=0.6179$

.6179
$51.07 \pm 2.330$

$49.50 \pm 2.863$

$t(38)=0.4269$

6719

$762.2 \pm 30.85$

$781.7 \pm 47.69$

$\mathrm{t}(38)=0.3434$

.7332

$61.67 \pm 2.050$

$60.64 \pm 2.352$

$\mathrm{t}(38)=0.33$

.7432 
Tail suspension test

$\left(\right.$ TRPM2 $^{-/} \mathrm{n}=15$, wt $\left.\mathrm{n}=19\right)$

Immobility (sec)

$130.0 \pm 17.91$

$101.7 \pm 28.35$

$t(32)=0.8789$

.3860 


\section{Highlights:}

Comprehensive behavioral analysis of TRPM2-deficient mice was performed

TRPM2-deficient mice show impaired behavioral flexibility

TRPM2-deficiency confers stress-resiliency 